\title{
Divergência genética entre genótipos de Mauritia flexuosa L. f. por meio de morfometria de frutos e sementes
}

\author{
Rosimeire Barboza BISPO ${ }^{1}$, Juliana de Freitas Encinas DARDENGO ${ }^{*}$, Rosimara Barboza BISPO', \\ Rosieli Barboza BISPO ${ }^{1}$, Ana Aparecida Bandini ROSSI ${ }^{1}$ \\ ${ }^{1}$ Universidade do Estado de Mato Grosso, Alta Floresta, MT, Brasil. \\ (Orcid: 0000-0002-3455-1084; *; 0000-0003-4154-1789; 0000-0003-1249-6974; 0000-0002-8318-5375) \\ *E-mail: ju_kk@hotmail.com (Orcid: 0000-0002-2086-4514)
}

Recebido em 12/07/2019; Aceito em 01/09/2020; Publicado em 11/09/2020.

\begin{abstract}
RESUMO: O objetivo do estudo foi caracterizar a variabilidade genética entre vinte genótipos de butiris $(M$. flexuosa L.f.) em vegetação natural nos municípios de Alta Floresta e Carlinda, MT, com base nas características morfológicas dos frutos e sementes, com o método de Otimização de Tocher, UPGMA e Análise de Componentes Principais. Foram amostrados 20 genótipos e avaliadas 8 caracteres morfológicos dos frutos e sementes. Os resultados foram obtidos através de medidas de Dissimilaridade, com o uso do programa GENES. O método de Tocher formou dois grupos, assim como o agrupamento UPGMA com corte a 80\%. Com os Componentes Principais houve a formação de três grupos. As três metodologias utilizadas revelaram que existe divergência genética entre os vinte genótipos de buritis avaliados. A divergência evidenciada neste trabalho permite inferir que para melhor representar a diversidade encontrada em $M$. flexuosa deve-se amostrar indivíduos pertencentes aos três grupos formados pela dispersão gráfica dos componentes principais, já que o dendrograma UPGMA também evidencia essa classificação, assim, pode-se indicar essas árvores para futuras pesquisas de melhoramento e conservação da espécie.
\end{abstract}

Palavras-chave: buriti; marcadores morfológicos; variabilidade genética.

\section{Genetic divergence among Mauritia flexuosa L. f. genotypes based on seed and fruit morphometry}

\begin{abstract}
The objective of the study was to characterize the genetic variability among twenty genotypes of M. flexuosa L. f. in natural vegetation in the municipalities of Alta Floresta and Carlinda, Mato Grosso state, Brazil, based on the morphological characteristics of the fruits and seeds, with the Tocher Optimization method, UPGMA and Principal Component Analysis. Twenty genotypes were sampled and eight morphological characteristics of fruits and seeds were evaluated. The results were based on the Dissimilarities Measures methodology, using the GENES program. The Tocher method formed two groups, as well as the UPGMA cluster with $80 \%$ cut. The Principal Components formed three groups. All methods used showed agreement on the formation of groups. The divergence presented in this research allows us to infer that in order to better represent the diversity found in $M$. flexuosa, individuals belonging to the three groups formed by the graphic dispersion of the principal components must be sampled, since the UPGMA dendrogram also shows this classification, so we indicate these trees for future breeding and conservation researches.

Keywords: buriti; morphological characteristics; genetic variability.
\end{abstract}

\section{INTRODUÇÃO}

O Buriti (Mauritia flexuosa L.f.) é uma palmeira pertencente à família Arecacea e a subfamília Lepidocarydeae, podendo ser encontrado na América do Sul, e no Brasil nos estados do Pará, Amazonas, Maranhão, Bahia, Piauí, Ceará, Tocantins e Mato Grosso (SANTOS et al., 2011). Apresenta capacidade de se desenvolver em diversos tipos de ambientes, como as matas de terra firme, matas periodicamente inundadas em áreas degradadas e nas baixadas úmidas no Cerrado do Brasil Central (LORENZI et al., 2004).

É considerada uma palmeira de estipe solitário e ereto, dificilmente inclinado, com diâmetro entre 30 e $60 \mathrm{~cm}$, os indivíduos adultos apresentam de 20 a 30 m (CAVALCANTE, 1991). Sua frutificação é sazonal e está relacionada com as condições edafoclimáticas, na maioria das regiões, ocorre nos meses de dezembro a junho (CARNEIRO; CARNEIRO, 2011)

M. flexuosa também apresenta importância estratégica na preservação da vida selvagem, já que o seu fruto é fonte de alimento para pássaros e mamíferos (GAZEL-FILHO; LIMA, 2001). A espécie geralmente apresenta frutos durante a estação da seca, proporcionando um estoque de alimento em momentos de escassez para os frugívoros destes ambientes (GOULDING; SMITH, 2007). Portanto, a preservação da diversidade genética e sua dinâmica natural são fundamentais quando são consideradas formas de uso dos recursos florestais.

$\mathrm{O}$ entendimento da diversidade genética através dos estudos de divergência, torna-se necessário no processo de identificação de novas fontes de genes de interesse 
(FALCONER; MACKAY, 1996) já que a diversidade genética intraespecífica pode ser vista como fundamental para a sustentabilidade e estabilidade do ecossistema (RAJORA; PLUHAR, 2003), sendo mantida pela divergência entre as plantas de uma mesma espécie.

A utilização de características morfológicas e o uso de técnicas estatísticas multivariadas são importantes para se avaliar a divergência genética do conjunto de genótipos estudados e verificar os caracteres que mais contribuem para a variabilidade genética nesses indivíduos (ELIAS et al., 2007).

Dos métodos de agrupamento, os mais utilizados são os de otimização e os hierárquicos (CRUZ et al., 2011). O método de otimização de Tocher consiste na formação de grupos cujas distâncias dentro dos grupos sejam menores que as distâncias entre grupos, assim, ao final do processo têm-se o número de grupos e os acessos contidos em cada grupo (CRUZ; CARNEIRO, 2003).

O método de agrupamento hierárquico UPGMA é sequencial, aglomerativo, sem superposições e com base na média aritmética, deste modo, a distância entre dois agrupamentos é a distância média entre todos os pares de observações, um em cada agrupamento (FARIA, 2009).

A análise por componentes principais consiste em transformar um conjunto original de variáveis em outro conjunto de dimensão equivalente. Cada componente principal é uma combinação linear das variáveis originais, sendo independentes entre si e obtidos com o propósito de reter o máximo da informação, em termos de variação total, contida nos dados iniciais (CRUZ et al., 2012).
Estas metodologias têm sido usadas para a quantificação da divergência genotípica e fenotípica em várias espécies nativas (LOBÃO et al., 2011; LOURENÇO et al., 2013).

Assim, a presente pesquisa tem como objetivo analisar a divergência genética entre vinte genótipos de buritis em vegetação natural nos municípios de Alta Floresta e Carlinda, Mato Grosso, com base em caracteres morfológicos de frutos e sementes, com uso do método de Otimização de Tocher, UPGMA e de Componentes Principais.

\section{MATERIAL E MÉTODOS}

A pesquisa foi realizada em populações naturais de $M$. flexuosa localizadas nos municípios de Alta Floresta e Carlinda, no norte do estado de Mato Grosso, a $830 \mathrm{~km}$ de Cuiabá. O relevo da região tem variação de sua ondulação, com prevalência de Latossolos Vermelho Amarelo, segundo a classificação de Köppen a região apresenta clima tipo Awi, sendo tropical chuvoso com estação seca nítida de dois meses, com temperatura anual entre 20 e $38^{\circ} \mathrm{C}$, tendo média de $26^{\circ} \mathrm{C}$ (FERREIRA, 2001).

Para realizar a caracterização morfológica, foram coletados e avaliados 600 frutos de vinte genótipos (30 de cada), com distância mínima de 20 metros entre as árvores. A coleta foi realizada entre os meses de outubro e novembro de 2014, em áreas de ocorrência natural da espécie. Os indivíduos representados pelos números de 1 à 10 foram coletados no município de Carlinda-MT (CA) (Figura 1) e os indivíduos de 11 à 20 no município de Alta Floresta-MT (AF) (Figura 1). Os genótipos foram amostrados aleatoriamente, sendo georeferenciados (latitude, longitude e altitude) através do Global Position System (GPS).
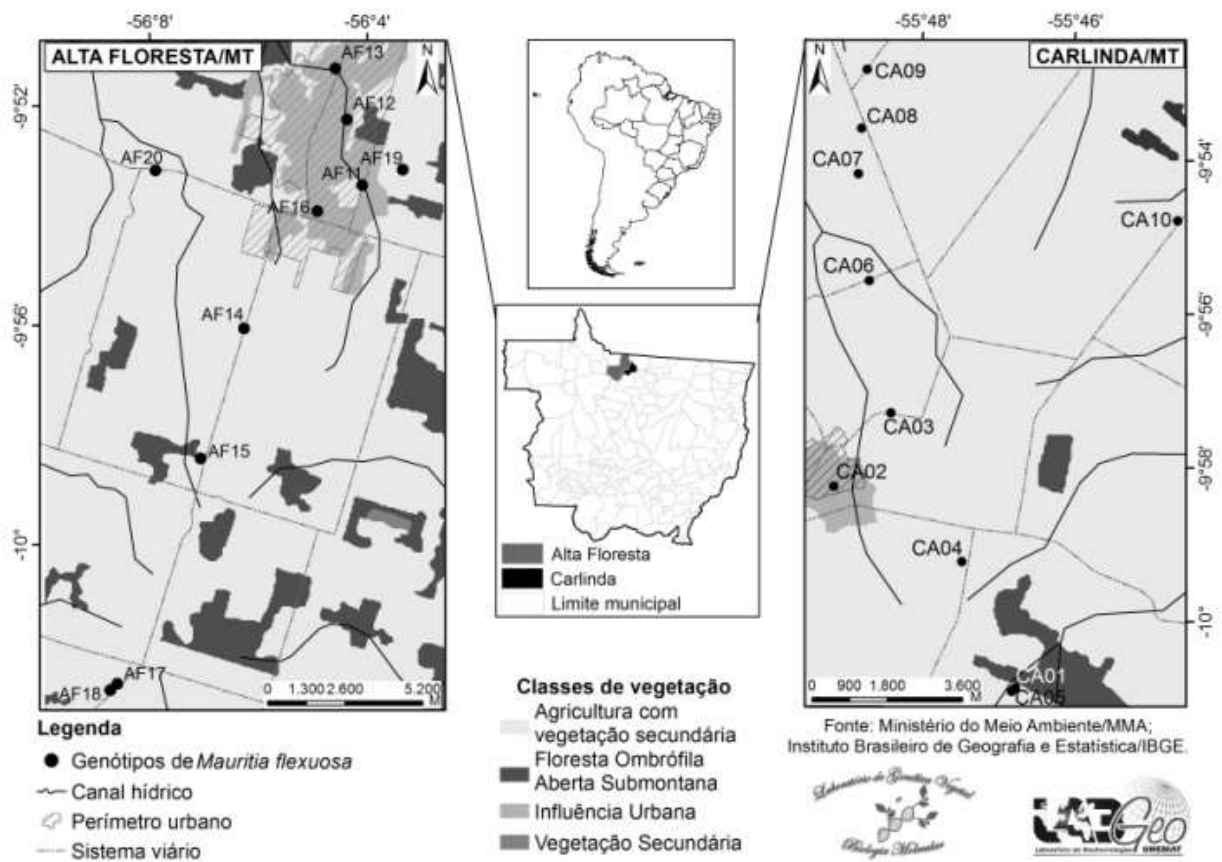

Figura 1. Localização Geográfica dos indivíduos de M. flexuosa amostrados no município de Alta Floresta e Carlinda - MT. FONTE: Ministério do Meio Ambiente (MMA) e Instituto Brasileiro de Geografia e Estatística (IBGE).

Figure 1. Geographic location of M. flexuosa individuals sampled in the municipalities of Alta Floresta and Carlinda, state of Mato Grosso. SOURCE: Ministry of Environment and Brazilian Institute of geography and statistics.

Para a avaliação biométrica foram mensuradas as seguintes características: largura do fruto (LF), comprimento do fruto $(\mathrm{CF})$, espessura do fruto $(\mathrm{EF})$, peso do fruto $(\mathrm{PF})$, espessura da semente (ES), comprimento da semente (CS), largura da semente (LS) e peso da semente (PS). Nas avaliações de peso foi utilizada uma balança de precisão 
$(0,01 \mathrm{~g})$, e as características de dimensões foram realizadas com o uso de paquímetro digital $(0,01 \mathrm{~mm})$.

Os dados foram obtidos no Laboratório de Genética Vegetal e Biologia Molecular da Universidade do Estado de Mato Grosso, Alta Floresta. Posteriormente, os dados foram avaliados utilizando a Distância Euclidiana Média Padronizada, segundo Cruz e Carneiro (2003), por meio de variáveis quantitativas. O agrupamento foi realizado pelo método UPGMA, de Tocher e de Componentes Principais com o uso do programa GENES (CRUZ, 2010).

\section{RESULTADOS}

A análise de grupamento gerada pelo método de Tocher (Tabela 1) separou os 20 genótipos de buritis em dois grupos distintos. O método de agrupamento por otimização ou método de Tocher constitui um método de agrupamento simultâneo, o qual realiza a separação dos genótipos em grupos de uma só vez. Esse método utiliza um único critério de agrupamento e possui a particularidade de apresentar a distância média dentro dos grupos sempre menor que a distância média entre os grupos. O grupo I reuniu 19 acessos, representando $90 \%$ dos genótipos avaliados e o grupo II com o acesso 10, indicando que os possíveis cruzamentos desses genótipos entre si diminuem a possibilidade de obtenção de genótipos com maior variabilidade.

O método de Tocher possibilitou estimar a dissimilaridade intra e intergrupo, a distância média intergrupo foi verificada entre os grupos I e II $(d 1 ; d 2=$ 49,39), enquanto a distância intragrupo ocorreu apenas no grupo $1(d 1=18,4)$, já que o grupo 2 foi formado apenas pelo indivíduo AF19.

O agrupamento dos genótipos promovidos pelo método UPGMA com corte a $80 \%$, corte apresentado com significância na análise do programa Genes (Figura 2) apresentou-se similar ao método de Tocher, alocando os genótipos em dois grupos. O grupo I formado por 19 dos 20 genótipos e o grupo II apresentando um único genótipo isolado (o AF19, também isolado no método de Tocher).
Os dados dos componentes principais permitiram verificar que a variação acumulada encontrada nos dois primeiros componentes explicou $93 \%$ da totalidade de variação dos 20 genótipos de buriti, sendo $81,14 \%$ na primeira e 11,86\% na segunda (Tabela 2).

Tabela 1. Agrupamento de 20 genótipos de Buriti pelo método de otimização de Tocher, baseado na distância euclidiana média padronizada, estimada a partir de 8 caracteres quantitativos de frutos e sementes.

Table 1. Grouping of 20 Buriti genotypes by the tocher optimization method, based on standardized mean Euclidean distance, estimated from 8 quantitative characters of fruits and seeds.

\begin{tabular}{ccc}
\hline Grupos & Genótipos & $\%$ de Genótipo \\
\hline & CA4, CA6, AF12, CA3, AF13, & \\
I & AF10, CA8, CA2, CA9, CA1, & $90 \%$ \\
& AF11, AF7, AF16, AF14, & \\
& AF18, 1AF7, AF20, CA5, AF15 & \\
\hline II & AF19 & $10 \%$ \\
\hline Total & 20 & $100 \%$ \\
\hline
\end{tabular}

Tabela 2. Estimativa dos autovalores associados aos componentes principais, importância relativa (raiz \%) e acumulada referente às oito características avaliadas em 20 genótipos de buritis.

Table 3. Estimation of the eigenvalues associated to the main components, relative importance (root \%) and accumulated referring to the eight characteristhics evaluated in 20 buritis genotypes.

\begin{tabular}{cccc}
\hline \multicolumn{4}{c}{ Estimativa dos autovetores } \\
\hline Componentes & Raiz & Raiz (\%) & $\%$ Acumulada \\
\hline 1 & 253,39 & 81,14 & 81,14 \\
2 & 37,03 & 11,86 & 93 \\
3 & 18,81 & 6,02 & 99,02 \\
4 & 2,09 & 0,67 & 99,69 \\
5 & 0,52 & 0,17 & 99,86 \\
6 & 0,25 & 0,08 & 99,94 \\
7 & 0,15 & 0,05 & 99,99 \\
8 & 0,02 & 0,006 & 100 \\
\hline
\end{tabular}

Ordem das características de maior peso nos últimos autovetores: 1. comprimento do fruto, 2. largura do fruto, 3. espessura do fruto, 4. peso do fruto, 5. comprimento da semente, 6. largura da semente, 7. espessura da semente, 8. peso da semente.

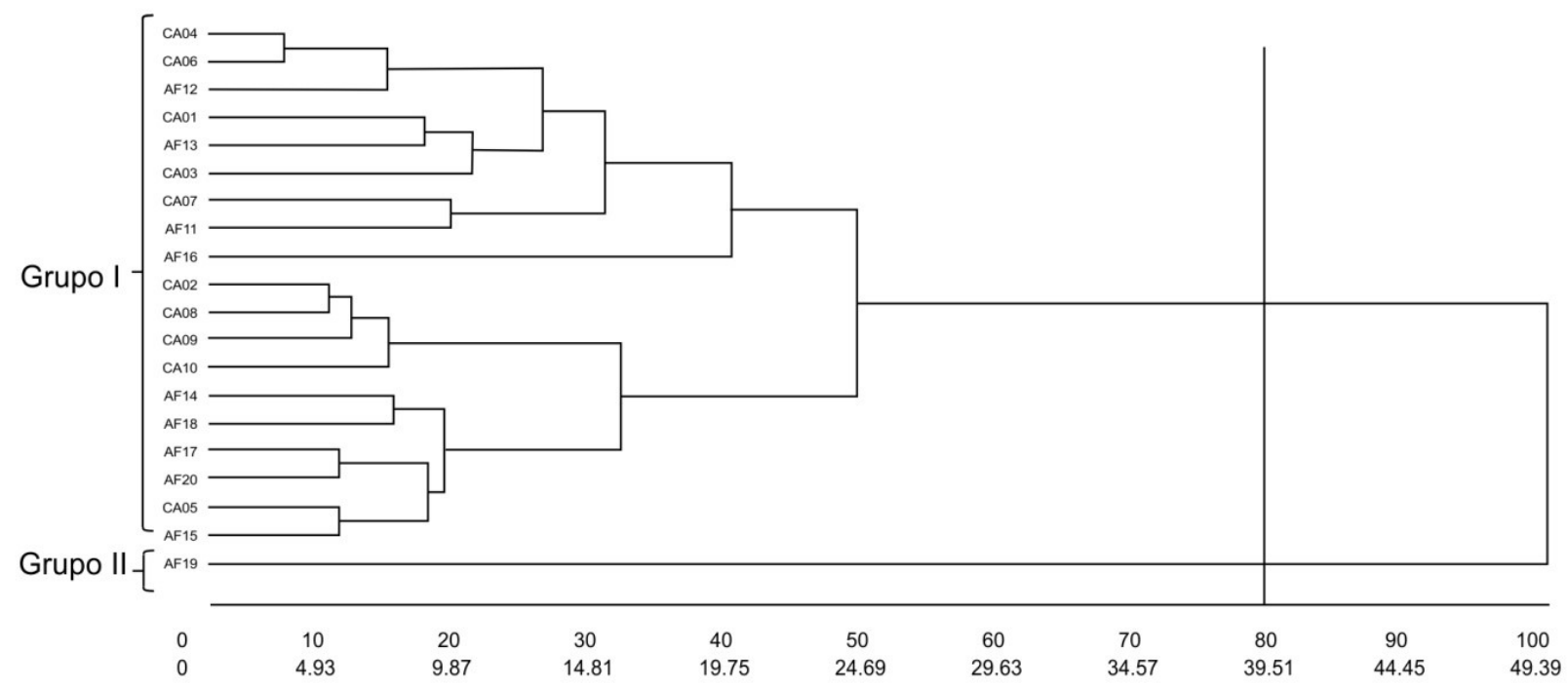

Figura 2. Dendrograma do padrão de dissimilaridade entre os 20 indivíduos de Buriti, obtido pelo Método de Agrupamento de Ligação Média entre Grupos (UPGMA) com base na Distância Euclidiana média padronizada, estimada a partir de 8 caracteres quantitativos de fruto e semente de Buriti.

Figure 2. Representative dendrogram of the dissimilarity pattern among the 20 Buriti individuals, obtained by the Mean Grouping Linkage Method (UPGMA) based on the Euclidian Distance, estimated from 8 quantitative characteristics of Buriti fruit and seed. 
A análise foi complementada pela dispersão gráfica (Figura 3), referente aos dois primeiros componentes principais. A representação gráfica permitiu inferir sobre o padrão de similaridade dos genótipos e os separou em três grupos, concordando parcialmente com os resultados obtidos pelos métodos de Tocher e UPGMA visto que manteve o genótipo AF19 isolado.

CP2

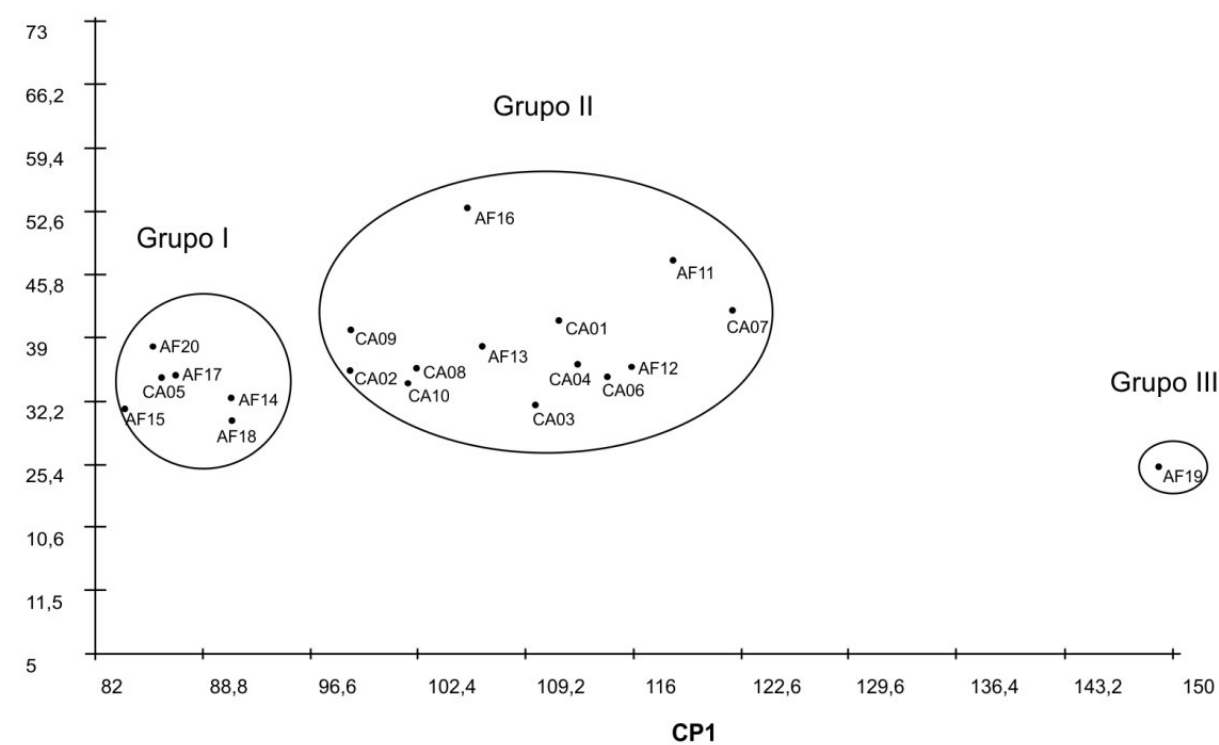

Figura 3. Dispersão gráfica em plano 2D de 20 genótipos de Buritis, em relação ao primeiro e segundo componente principal (CP1 e CP2) com base em 8 variáveis multicategóricas avaliadas em frutos e sementes de $M$. flexuosa. CP1: 81,14\% e CP2: 11,86\%

Figure 3. 2D plot of 20 Buritis genotypes in relation to the first and second principal component (CP1 and CP2) based on 8 multicategoric variables evaluated in fruits and seeds of $M$. flexuosa. CP1: 81,14\% and CP2: $11,86 \%$

\section{DISCUSSÃO}

A análise gerada pelo método de Tocher separou os 20 genótipos de buritis em dois grupos distintos. Resultado semelhante foi verificado no estudo de Almeida et al. (2011), em que o uso do método de Tocher possibilitou a separação das doze cultivares avaliadas em dois grupos, sendo o grupo I composto por onze das doze cultivares analisadas.

O método de Tocher apresenta na maioria dos casos, cada genótipo formando um grupo específico (um grupo de apenas um genótipo) em virtude de este agrupamento ser influenciado pela distância dos genótipos já agrupados (Vasconcelos et al., 2007).

Discriminar os indivíduos mais dissimilares é importante para futuros programas de melhoramento da espécie, pois segundo Bispo et al., (2014), a combinação entre indivíduos alocados em diferentes grupos pode fornecer indivíduos com maior variabilidade.

Para o grupo II não foi possível obter a distâncias intragrupo, já que foi formado por um único genótipo (AF19), sendo este o mais dissimilar, apresentando frutos maiores e evidentemente mais pesados, podendo ser uma variação própria do seu material genético ou influenciada por condições ambientais.

Matos et al. (2014), estudando a mesma espécie verificaram que $87,5 \%$ das maiores médias morfométricas de frutos e sementes foram encontradas em árvores localizadas em áreas que sofreram menores intervenções antrópicas. Da mesma forma Barbosa et al. (2009) em pesquisa com buriti na Amazônia, observaram que em áreas com constante interferência do fogo e infertilidade do solo, os indivíduos apresentaram floração e frutificação comprometidas em relação às áreas florestais mais férteis e úmidas. Sendo assim, a dissimilaridade evidenciada para o genótipo AF19 corrobora em parte com o resultado dos supracitados autores, já que esse genótipo se encontra próximo a uma área antropizada, porém com boa disponibilidade de água, o que possibilita seu bom estabelecimento. Conforme Real (1980), a variação no tamanho de frutos e sementes dentro de uma mesma espécie representa uma resposta evolutiva às incertezas em relação ao estabelecimento das plantas, gerados pela heterogeneidade do habitat e inimigos naturais.

Através da análise do dendrograma verifica-se que os genótipos de ambas as localidades foram estabelecidos no grupo 1, evidenciando que a similaridade dos ambientes em que os genótipos estão inseridos pode ter influenciado nas características dos frutos e sementes. Esses dados corroboram com o trabalho de Manfio (2010), que estudando a diversidade genética de macaúba baseada em características dos frutos, detectou cinco grupos formados por matrizes de mais de uma procedência, sem correlação com a origem geográfica.

A variação acumulada nos dois primeiros componentes explicou $93 \%$ da variação total obtida nos indivíduos de buriti. Segundo Cruz et al. (2012) a análise de componentes principais é utilizada quando os primeiros componentes envolvem pelo menos $80 \%$ da variação total, possibilitando a avaliação da importância de cada caractere estudado sobre a variação total disponível entre os indivíduos.

A variação nos dois primeiros componentes principais neste estudo foi maior do que a encontrada por Galete et al. (2012) estudando características morfométricas do fruto de Euterpe oleracea em que obtiveram $91,34 \%$ da variação total apenas no décimo primeiro componente. Oliveira et al. (2014) obtiveram resultados semelhante a este estudo, com 
cerca de $94 \%$ da variação total nos dois primeiros componentes, em sua pesquisa com caracteres morfológicos de cagaiteira (Eugenia dysenterica DC.), entre os quais estão características dos frutos.

\section{CONCLUSÕES}

O agrupamento formado pelo método de Tocher, método hierárquico UPGMA e Análise de Componentes Principais foram eficientes ao avaliar a divergência entre os vinte genótipos de $M$. flexuosa analisados, revelando que há variabilidade entre todos os genótipos avaliados.

Os dados obtidos nos dois métodos de agrupamento e de Componentes Principais apresentaram-se concordantes, principalmente no que se refere ao isolamento do genótipo AF19. A divergência evidenciada neste trabalho permite inferir que para melhor representar a diversidade encontrada em $M$. flexuosa deve-se amostrar indivíduos pertencentes aos três grupos formados pela dispersão gráfica dos componentes principais, já que o dendrograma UPGMA também evidencia essa classificação, assim, pode-se indicar essas árvores para futuras pesquisas de melhoramento e conservação da espécie.

\section{REFERÊNCIAS}

ALMEIDA, R. D.; PELUZIO, J. M.; AFFÉRRI, F. S. Divergência genética entre cultivares de soja, sob condições de várzea irrigada, no sul do Estado Tocantins. Revista Ciência Agronômica, Uberlândia, v. 42, n. 1, p. 108-115, 2011.

BARBOSA, R. I.; LIMA, A. D.; MOURÃO JÚNIOR, M. Biometria de frutos do buriti (Mauritia flexuosa L.f. - Arecaceae): estimativas de produtividade de polpa e óleo vegetal em uma área de savana em Roraima. Instituto Nacional de Pesquisa da Amazônia. 2009.

BISPO, R. B.; ROSSI, A. A. B.; BISPO, R. B.; BISPO, R.B.; DARDENGO, J. F. E. Análise da divergência genética de tamarindeiros cultivados em quintais no município de Alta floresta, MT por meio de diferentes métodos de agrupamento. Enciclopédia Biosfera, Goiânia, v. 10, n. 19, p. 1978-1987, 2014.

CARNEIRO, T. B.; CARNEIRO, J. G. M. Frutos e polpa desidratada Buriti (Mauritia flexuosa L.): aspectos físicos, químicos e tecnológicos. Revista Verde de Agroecologia e Desenvolvimento Sustentável, Pombal, v. 6, n. 2, p. 105-111, 2011.

CAVALCANTE, P. B. Frutas Comestíveis da Amazônia Belém: CEJUSP/CNPq Museu Paraense Emílio Goeldi, (Coleção Adolfo Ducke), p. 279, 1991.

CRUZ, C. D. Programa Genes -Versão Windows. Viçosa; UFV. 284p. 2010.

CRUZ, C. D.; CARNEIRO, P. C. S. Modelos biométricos aplicados ao melhoramento genético. Viçosa: Editora UFV, vol. 2, cap. 6, 2003. p. 357-434.

CRUZ, C. D.; FERREIRA, F. M.; PESSONI, L. A. Biometria aplicada ao estudo da diversidade genética. Visconde do Rio Branco: Suprema, 2011. 620p.

CRUZ, C. D.; REGAZZI, A. J.; CARNEIRO, P. C. S. Modelo biométrico aplicado ao melhoramento genético. Viçosa: Editora UFV, v.1, 514p. 2012.
ELIAS, H. T.; VIDIGAL, M. C. G.; GANELA, A.; VOGOT, G. A. Variabilidade genética em germoplasma tradicional de feijão-preto em Santa Catarina. Pesquisa Agropecuária Brasileira, Brasília, v. 42, n. 10, p. 14431449, 2007. DOI: 10.1590/S0100-204X2007001000011.

FALCONER, D.S.; MACKAY, T.F.C. Introduction to quantitative genetics. London: Longman, 464p. 1996.

FARIA, P. N. Avaliação de métodos para determinação do número ótimo de clusters em estudo de divergência genética entre acessos de pimenta. 54p. Dissertação (Mestrado em Estatística Aplicada e Biometria) - Universidade Federal de Viçosa, Viçosa, 2009.

FERREIRA, J. C. V. Mato Grosso e seus municípios. Cuiabá: Secretaria de Estado da Educação. 365p. 2001.

GALETE, R. S.; MOTA, M. G. C.; GAIA, J. M. D. Caracterização morfoagronômica de germoplasma de açaizeiro no Nordeste paraense. Revista Brasileira de Fruticultura, Jaboticabal, v. 34, n. 2, p. 540-550, 2012.

GAZEL-FILHO, A. B. G.; LIMA, J. A. S. O Buritizeiro (Mauritia flexuosa) e seu potencial de utilização. Macapá: EMBRAPA, 342p. 2001.

GOULDING, M.; SMITH, N. Palmeiras: sentinelas para a conservação da Amazônia. Lima, Peru: Amazon Conservation Association, 358p. 2007.

LOBÃO, M. S.; CASTRO, V. R.; RANGEL, A.; SARTO, C.; TOMAZELLO FILHO, M.; SILVA JÚNIOR, F. G.; CAMARGO NETO, L.; BERMUDEZ, M. A. R. C. Agrupamento de espécies florestais por análises univariadas e multivariadas das características anatômica, física e química das suas madeiras. Scientia Forestalis, Piracicaba, v. 39, n. 92, p. 469-477, 2011.

LORENZI, H.; SOUZA, H. M.; CERQUEIRA, L. S. C.; MEDEIROS-COSTA, J. T.; FERREIRA, E. Palmeiras brasileiras e exóticas cultivadas. Nova Odessa, SP: Instituto Plantarum. 416p. 2004.

LOURENÇO, I. P.; FIGUEIREDO, R. W.; ALVES, R. E.; ARAGÃ̃O, F. A. Z.; MOURA, C. F. H. Caracterização de frutos de genótipos de muricizeiros cultivados no litoral cearense. Revista Ciência Agronômica, Fortaleza, v. 44, n. 3, p. 499-504, 2013.

MANFIO, C. E. Análise genética no melhoramento da macaúba. Tese (Doutorado em Genética e Melhoramento) - Curso de Pós Graduação em Genética e Melhoramento. Universidade Federal de Viçosa, Viçosa. 2010.

MATOS, F. S.; NUNES, Y. R. F.; SILVA, M. A. P.; OLIVEIRA, I. S. Variação biométrica de diásporos de buriti (Mauritia flexuosa L.f. - Arecaceae) em veredas em diferentes estágios de conservação. Ciência Florestal, Santa Maria, v. 24, n. 4, p. 833-842, 2014. DOI: 10.1590/1980-509820142404004.

OLIVEIRA, T. C.; GONÇALVES, D. L.; ELIAS, J. C. F.; CASTRO, M. S.; BARELLI, M. A. A. Caracterização morfológica de acessos de cagaiteira na região de CáceresMT. Agrarian Academy, Goiânia, v. 1, n. 2, p. 26-36, 2014. DOI: 10.18677/Agrarian_Academy 2014_027

RAJORA, O. P.; PLUHAR, S. A. Genetic diversity impact of Forest fire, Forest harvesting and altenative reforestation pratices in black spruce (Picea mariana). Theoretical and Applied Genetics, Berlim, v. 106, n. 7, p. 1203-1212, 2003. DOI: $10.1007 / \mathrm{s} 00122-002-1169-9$ 
REAL, L. A. Fitness, uncertainty, and the role of diversification in evolution and behavior. American Naturalist, Chicago, v. 115, p. 623-638, 1980.

SANTOS, C. A.; RIBEIRO, R. C.; SILVA, V. C.; SILVA, N. S.; SILVA, B. A.; SILVA, G. F.; BARROS, B. C. V. Elaboração de biscoito de farinha de buriti (Mauritia flexuosa L. f) com e sem adição de aveia (Avena sativa L.). Revista Brasileira de Tecnologia Agroindustrial, v. 5, n. 1, p. 262-273, 2011. DOI: 10.3895/S198136862011000100002.

VASCONCELOS, E. S; CRUZ, C. D.; BHERING, L. L.; RESENDE JUNIOR, M. F. R. Método alternativo para método de agrupamento. Pesquisa Agropecuária Brasileira, Brasília, v. 42, n. 10, p. 1421-1428, 2007. 